\title{
CIÊNCIA, TECNOLOGIA E INOVAÇÃO: A IMPORTÂNCIA DOS SISTEMAS ESTADUAIS EM UMA ESTRATÉGIA NACIONAL PARA O SETOR NO BRASIL ${ }^{1}$
}

\author{
SCIENCE, TECHNOLOGY AND INNOVATION SYSTEMS: APPROACHING THE ROLES AND \\ CHALLENGES OF STATE RESEARCH SUPPORT AGENCIES IN BRAZIL
}

\author{
CIENCIA, TECNOLOGÍA E INNOVACIÓN: LA IMPORTANCIA DE LOS SISTEMAS DE CADA ESTADO EN \\ UNA ESTRATEGIA NACIONAL PARA EL SECTOR EN BRASIL
}

Wellington Lourenço de Almeida Doutor em Ciência Política Universidade de São Paulo (USP) São Paulo, SP, Brasil walmeida@unb.br

Resumo: Este artigo analisa aspectos institucionais da trajetória das Fundações Estaduais de Amparo à Pesquisa (FAPs) no Brasil. A abordagem está estruturada a partir dos desafios colocados pela Agenda 2030 das Nações Unidas, especialmente em seu objetivo 9, que trata da necessidade de construção de infraestruturas resilientes, buscando promover a industrialização inclusiva e sustentável, além de fomentar a inovação. A pesquisa procura identificar possíveis caminhos para o fortalecimento institucional desse sistema. Trata-se de uma pesquisa exploratória que se apoiou em metodologia triangular, por meio da articulação entre literatura, revisão de documentos oficiais e geração de dados, além da experiência prática vivenciada pelo autor ${ }^{2}$. A agenda 2030 das Nações Unidas é uma carta de intenções firmada em ambiente multilateral, expressando consenso sobre um cenário ideal, sem análise dos entraves inerentes aos desafios reais nos planos doméstico e global. Isto não anula sua importância como uma visão de futuro capaz de orientar ações por parte dos atores políticos e sociais. Neste ensaio, ela é entendida como uma oportunidade de se buscar uma reflexão estratégica em uma área decisiva para o futuro ou não futuro do país. O exame se concentra nas tendências centrais das mudanças societárias em curso, apontadas pela literatura. A partir dessa descrição, procura refletir sobre as respostas dadas pelo país nos últimos anos, discutindo, também, percepções sobre o que poderá ocorrer no futuro próximo, extraídas de um diálogo com atores-chave do setor das FAPs em nível subnacional.

Palavras-chave: Agenda 2030; Nações Unidas; fundações; pesquisa; inovação.

Abstract: This article addresses some key institutional aspects of the history of state research support foundations in Brazil (FAPs, in the national acronym). It also assesses relevant possibilities linked to their subnational system - a structure that emerged in the previous three decades -, considering the current dilemmas that result from the lack of a more proactive strategy in the field. This is an exploratory research based on a triangulation-methodology that combines field literature, a review of official documents, data production and institutional experience. This contribution is not focused on the current aspects and challenges of science and research in the country - a field undergoing an acute funding crisis and facing the threat of serious disruptions. Instead, it examines the trends and societal changes pointed out by the recent literature. It is a reflection on the country's responses to these challenges in recent years and a discussion of perceptions of what may take place in the near future, based on interviews with representatives of key subnational actors from the field. This is an effort to conceive an agenda which, nonetheless, will only be feasible with a change in the country's current political context.

Keywords: 2030 Agenda; United Nations; foundations; research; innovation.

Resumen; Este artículo analiza aspectos institucionales de la trayectoria de las Fundaciones de Apoyo a la Investigación (FAPs, en la sigla en portugués) en Brasil. El abordaje se estructura a partir de los retos establecidos por la Agenda 2030 de las Naciones Unidas, principalmente su objetivo 9 . La investigación busca identificar posibles caminos para el fortalecimiento institucional de este sistema. Se trata de una investigación exploratoria que se apoyó en una metodología triangular, mediante una articulación entre literatura, revisión de documentos oficiales y generación de datos, además de contar con la experiencia práctica vivida por el autor. La Agenda 2030 de las Naciones Unidas es una carta de intenciones firmada en un ambiente multilateral, que manifiesta un consenso sobre un escenario ideal, sin analizar los obstáculos asociados a los desafíos reales en los planos doméstico y global. Eso no invalida su importancia como una visión de futuro capaz de orientar acciones por parte de los actores políticos y sociales. En este ensayo, esta se entiende como una oportunidad para buscar una reflexión estratégica en un área decisiva para el futuro, o no futuro, del país y se concentra en las tendencias centrales de los cambios societarios en curso, expuestos en la literatura. A partir de esta descripción se intenta reflexionar sobre las respuestas que ha dado el país, durante los años recientes, bien como discutir ciertas percepciones sobre qué podrá suceder en un futuro cercano, con base en un diálogo con actores que actúan en el sector de las FAPs en el ámbito subnacional.

Palabras clave: Agenda 2030; Naciones Unidas; fundaciones; investigación; innovación.

\section{Para citar - ABNT NBR 6023:2018}

ALMEIDA, Wellington Lourenço de. Ciência, tecnologia e inovação: a importância dos sistemas estaduais em uma estratégia nacional para o setor no Brasil. Cadernos de Pós-graduação, São Paulo, v. 20, n. 1, p. 91-110, jan./jun. 2021. Disponível em: https://doi.org/10.5585/cpg.v20n1.19423

\footnotetext{
${ }^{1}$ Síntese de pesquisa apoiada pela Escola Nacional de Administração Pública (ENAP), através do Programa Cátedras Brasil, edital 2018.

${ }^{2} \mathrm{O}$ autor foi presidente da Fundação de Apoio à Pesquisa do Distrito Federal (FAPDF) entre outubro de 2016 e dezembro de 2017.
} 


\section{Introdução}

\section{Contexto e literatura}

Um primeiro exercício sobre as potencialidades do Brasil - olhando para os objetivos das áreas de ciência e tecnologia da Agenda 2030 - (BRASIL, 2016) impõe, de partida, duas análises sobre os cenários das mudanças globais que (re)configuram a sociedade contemporânea. As mudanças aqui referidas dizem respeito especialmente aos impactos provocados pelas alterações no padrão tecnológico dominante. A primeira seria uma releitura das alterações perceptíveis, mensuradas e já analisadas. A segunda nos leva a uma leitura prospectiva das grandes tendências que poderão impactar os processos de mudanças em curso na atual sociedade do conhecimento, especialmente em relação à percepção e preparação interna de nosso país para responder a esse cenário. Nesses dois exercícios, é necessário identificar o comportamento do país no passado recente, seus erros e acertos, e os desafios e impasses do futuro próximo.

Esta pesquisa se apoiou teoricamente no conceito de sociedade em rede, revisto e sintetizado por Castells (2011), que nos oferece um pensamento estruturante para se discutir os contornos da sociedade contemporânea, fruto de uma duradoura e extensa pesquisa empírica e teórica. Esse conceito sustenta a ideia de que na virada do século passado, um conjunto de mudanças sociais, tecnológicas, econômicas e culturais deram contorno a um novo tipo de sociedade. Uma nova sociedade formada por redes, impossível de ser totalmente compreendida pelas categoriais intelectuais predominantes no século XX. Fazendo um balanço destas mudanças, Castells resgata a importância de se entender a teoria e a própria investigação na dimensão de utilidade que procura dar sentido aos temas observados. Assim, a investigação social não justifica seu valor somente pela coerência, mas também pela sua relevância. Em síntese, não é um discurso, mas, essencialmente, uma investigação. Mostra, ainda, que dois campos principais dessa transformação tecnológica atuam de maneira inter-relacionada e alteram profundamente as bases materiais de nossas vidas. Trata-se da comunicação baseada na microeletrônica e na engenharia genética. A sociedade em rede, tecnologicamente estruturada, radicalizou ainda mais o processo de globalização que se diversifica para além de sua vertente financeira hegemônica.

Essas mudanças estruturais desafiam todas as sociedades. As mais pobres são praticamente excluídas desse processo. Países em desenvolvimento que contam com capacidade instalada em termos tecnológicos, mas não participam das principais decisões que movimentam o capitalismo global, também correm o risco de se tornar irrelevantes. O Brasil faz parte desse segundo grupo e está cada vez mais desafiado a manter a capacidade de dar prosseguimento às suas políticas de inovação. Entrar nesse jogo, buscar caminhos que possam inserir o país em condições vantajosas ou melhores do que as atuais, pressupõe compreender a intrínseca relação entre as novas formas 
do capital neste século, seu desenvolvimento tecnológico e a produção do conhecimento, como argumenta Giannotti (2017). Descrever esse objeto para buscar compreender as tendências atuais e indicar prospecções sobre o que teremos pela frente, no horizonte de 2030, não é uma tarefa simples. Ademais, demanda atualização permanente, pois os processos em curso detonam outros, imprevisíveis. Diante dessa limitação e buscando compreender especificamente o que se passa no Brasil, nesta área, podemos iniciar a construção de um mapa limitado e parcial, olhando tanto para os grandes recortes das megatendências quanto para um diagnóstico sobre o que está sendo feito ou não no país, em áreas decisivas, para se falar em preparação para uma agenda de nova industrialização, levando em conta os desafios descritos por Castells.

Os impactos provocados pelas inovações tecnológicas têm uma capacidade desagregadora, especialmente em sociedades com alto perfil de desigualdade e baixo perfil educacional - caso do Brasil. Nesse sentido, o que se vislumbra, por exemplo, para o mercado de trabalho e a capacidade de governança em diversas áreas é preocupante. Gaetani e Almeida (2019) apresentam inúmeros exemplos desses desafios, o que está sendo feito em alguns países e o que não está sendo feito no Brasil. A questão central para eles é o fato de que a reestruturação produtiva que vem ocorrendo nas economias desenvolvidas e em duas grandes economias de países em desenvolvimento (China e Índia) pegou o Brasil 'no contrapé', politicamente conflagrado, e sem consenso razoável quanto a um projeto nacional mínimo. Nesse contexto, crescem as dificuldades para acompanhar o movimento em torno do conceito de interconexão que organiza as atividades econômicas contemporâneas. Estas são cada vez mais intensivas em tecnologias digitais.

Os autores pontuam, para exemplificar o processo em curso, que a inteligência artificial vem sendo comparada à eletricidade em termos de impacto no modo de viver e produzir. Inteligência Artificial pode ser definida como a área da ciência da computação que possibilita a realização de tarefas inerentes ao raciocínio humano por sistemas de computador, tais como o reconhecimento de padrões visuais, tomadas de decisão, reconhecimento de voz e tradução de idiomas, entre outros. Existem diversas abordagens para aproximar programas a comportamentos "inteligentes". Atualmente, com a explosão de dados gerados pela sociedade e a disponibilidade de recursos para armazená-los e processá-los rapidamente - o chamado Big Data -, uma subárea da Inteligência Artificial ganha destaque: a aprendizagem feita por máquina (Machine Learning). ${ }^{3}$

Esse avanço digital vem colocando em xeque os conhecimentos e habilidades hegemônicas no mundo do trabalho, cuja face mais visível é a obsolescência de algumas profissões que deverão desaparecer no futuro próximo. A reação a esse processo vem mobilizando governos, o mundo

\footnotetext{
${ }^{3} \mathrm{O}$ conceito busca traduzir um sistema de aprendizagem "desenvolvido" por máquinas, mas não é possível precisá-lo com essa tradução direta. Assim, optou-se por manter o termo Machine Learning, além do conceito em si, que advém da área de ciência da computação. Neste caso, a opção é didática, pois o objetivo aqui é de sintese. Uma abordagem mais detalhada deve necessariamente trabalhar com o conceito de ciência de dados, que é mais abrangente, por conta de sua visão multidisciplinar.
} 
privado e organizações dos trabalhadores em inúmeros países, por meio de programas de massificação e qualificação profissional em bases digitais. Mas no Brasil, esse movimento se restringe a ações isoladas, incapazes de responder a essas mudanças. É preciso se preparar como país para o enfrentamento desse contexto de radicais mudanças em curso. Trata-se de uma questão de responsabilidade para todos os atores interessados em viabilizar um novo projeto de desenvolvimento, capaz de ao menos retirar, no médio prazo, o país do espaço secundário que hoje ocupa na divisão internacional do trabalho, como resultado da sua crescente dependência dos preços das commodities.

Essa análise dos cenários certamente não deve significar a adesão acrítica e ingênua a uma lógica dominante que se impõe a partir do centro do sistema. Trata-se, primeiramente, de aceitar como um dado da realidade que o sistema de produção e trocas de bens é único no sentido de hegemonia, embora atores centrais como China e Rússia, por exemplo, estejam, ao mesmo tempo, dentro e fora dele. Estão fora no sentido político mais amplo, pois têm poder acumulado na economia (China) e militar (Rússia) para resistir às naturais pressões dos países mais ricos e desenvolvidos. No Brasil, o fim do padrão de acumulação que se impôs após a experiência do nacionaldesenvolvimentismo (com a industrialização por substituição de importações) não foi capaz de gerar, nas três décadas recentes, políticas bem coordenadas, que garantam o planejamento e a expansão da capacidade produtiva, com atualização da infraestrutura e desenvolvimento de novas vantagens competitivas (SAAD FILHO; MORAES, 2018). Alterar esse padrão é também uma tarefa essencial para reinserir a área de ciência e tecnologia do país em uma estratégia de longo prazo.

O objetivo central deste artigo é chamar atenção para as medidas institucionais adotadas pelo Brasil, nas décadas recentes, em relação ao setor de ciência, tecnologia e inovação. Essas ações demandam políticas articuladas em vários campos, especialmente na educação. Tomando como parâmetro os compromissos assumidos pelo país na Agenda 2030 das Nações Unidas, o texto procura recuperar os esforços feitos, argumentando que eles não foram suficientes para definir uma estratégia consistente. A partir das carências identificadas, a pesquisa procura explorar o potencial de contribuição dos atores subnacionais (as fundações estaduais de apoio ao setor) na estruturação dessa necessária estratégia. Assim, são apresentados em sequência os principais dilemas identificados e as tentativas de adequação do marco legal, que tiveram como objetivo buscar saídas para a área. Completa a análise uma pesquisa qualitativa realizada com gestores que ocupam ou ocuparam posições-chave no processo decisório em nível estadual. 


\section{Necessidade de estratégia}

O Brasil optou, via pacto da Constituição em 1988, pela construção de uma sociedade democrática e aberta, que procura se consolidar com imensas dificuldades. Assim, o desafio institucional é complexo e demanda a solidificação de ideias-força para enfrentar os próprios riscos da inovação. Um deles, como aponta Rodrik (2015; 2016), é evitar que as inovações permaneçam concentradas em poucos setores intensivos em tecnologia, que absorvem os profissionais mais qualificados, mas representam uma parcela pequena do PIB. Reverter tal tendência implica disseminar a inovação para a maior parte da economia, pois o impacto positivo da inovação para a produtividade, o emprego e a equidade dependem de como ela é disseminada no mercado de trabalho, de produtos e serviços. Mesmo na Europa, que concentra algumas das economias mais avançadas em tecnologia e inovação, há uma forte preocupação com esse risco, que vem sendo enfrentado recentemente com as estratégias de disseminação de inovação aberta, que procura envolver o máximo de setores produtivos, públicos e sociais (EUROPEAN COMMISSION, 2016).

A premissa de inovação aberta nessa política europeia consiste em conceber a dinâmica de inovação enquanto uma interação entre todos os atores envolvidos no processo de conhecimento. Fazer o conhecimento circular passa a ser um elemento crucial para a criação de novos produtos e a disseminação do que hoje é definido como cultura empreendedora. Esta noção advoga a necessidade de transferência de conhecimento, habilidades e recursos em mão dupla entre instituições de pesquisas e empresas. Demanda, assim, uma mudança de paradigma, transitando da ideia linear e bilateral de colaboração para um novo patamar mais dinâmico, focado em redes e ecossistemas de inovação multicolaborativos. Esta nova dinâmica é incompatível com a ideia de resultados prédefinidos em estratégias isoladas de inovação visando a patentes e à comercialização. Assim, os resultados viriam de um processo mais complexo de criação compartilhada, envolvendo o conhecimento resultante da circulação de ideias e propostas no ambiente econômico e social. A chave para garantir essa transição da transferência linear de conhecimento, estabelecendo, também, uma conexão com a proposta de ciência aberta, exigirá, de acordo com essa estratégia, a criação e o apoio a ecossistemas de inovação com capacidade de disseminar o conhecimento como um valor social e compartilhado por toda a sociedade.

Ciência aberta significa um modelo baseado em trabalho cooperativo e atualização das estratégias de difusão do conhecimento, utilizando tecnologias digitais e novas ferramentas colaborativas. Dessa forma, seria necessária uma completa inversão das estratégias utilizadas nos 50 anos anteriores, baseadas na prática de mera publicação de resultados de pesquisas em periódicos científicos, para um novo patamar de disponibilização para uso do conhecimento já nas fases iniciais do processo de pesquisa, em um novo modelo de trabalho em rede e uma nova relação social entre 
ciência e sociedade. A despeito dos naturais conflitos políticos e econômicos que, naturalmente, desafiam estratégias amplas dessa natureza, os princípios e ideias-força por trás dos conceitos de inovação e ciência aberta respondem claramente, no contexto europeu, aos desafios para economias que já vivenciam um elevado grau de inovação, e que pretendem continuar desempenhando um papel de vanguarda.

Uma análise comparativa, mesmo limitada - neste caso, apenas olhando para as características gerais da estratégia europeia -, ajuda-nos a compreender melhor os nossos problemas. As tensões naturais da democracia não podem impedir que ocorra algum grau de cooperação para que possamos definir minimamente um projeto estratégico para o país. E para isso, o maior erro é acreditar que existem receitas prontas, adaptáveis a qualquer situação. Não há - como bem mostram, com rara clareza, os exemplos de estratégias diferenciadas citados por Rodrik (2011) sobre os paradoxos da globalização. Na experiência recente na América Latina, sustenta Rodrik (2016), a despeito das relevantes inovações nas empresas bem administradas e em setores de vanguarda, a economia, em seu conjunto, estagnou. Este paradoxo é explicado pelo fato de que o rápido crescimento da produtividade em nichos de inovação acaba sendo anulado pela migração de trabalhadores dos setores mais produtivos para os menos produtivos da economia. Dessa forma, seu argumento principal é que, embora crucial para a economia contemporânea, as inovações per se não elevam os padrões de vida de uma sociedade, pois podem também se restringir aos bolsões tecnológicos, convivendo lado a lado com baixa produtividade. O impacto positivo dependerá sempre de um impacto abrangente no conjunto da economia.

Dessa forma, é relevante insistir, ainda, no debate sobre os arranjos institucionais possíveis para que uma estratégia mínima se afirme no Brasil. A rigor, não podemos reconhecer que existe ou existiu no passado recente algo parecido nessa área. Mas esforços foram feitos - especialmente na formulação de propostas -, e eles podem ser um ponto de re(partida), aproveitando a experiência das tentativas desenhadas. Em 2016, foi lançada a Estratégia Nacional de Ciência, Tecnologia e Inovação (ENCTI) (BRASIL, 2016a), voltada à criação de um consenso entre os principais atores que deveriam dialogar com o tema, em caráter sistêmico. Entre esses atores, estão os principais representantes nas diversas esferas dos poderes Executivo e Legislativo (ministérios, agências reguladoras, secretarias estaduais e municipais, o Congresso Nacional e as assembleias estaduais), bem como as sociedades científicas, o mundo empresarial, as agências de fomento, universidades e institutos federais e estaduais de ciência e tecnologia, entre outros.

A existência, ou não, de uma estratégia nessa área faz toda a diferença para o reposicionamento frente aos processos de reconfiguração tecnológica e econômica em curso. Temos o desafio de encontrar um novo espaço no mundo, a partir de um consenso razoável sobre nossos principais 
interesses, pois somos muito grandes para vincular nosso destino a qualquer bloco ou potência. Nesse sentido, aumentar nossa capacidade em pesquisa e elevar radicalmente o nível educacional no país são condições essenciais para que o Brasil possa falar em futuro. No bojo da economia de conhecimento, uma nova onda parece se formar, invertendo a lógica das décadas recentes, quando empresas transnacionais moviam suas plantas pelo mundo em busca de mão de obra mais barata, conforme descrevem Lund, Manyika e Spence (2019). Essa é mais uma consequência da complexa e moderna produção de bens, baseada mais em pesquisa e planejamento.

Com o comércio cada vez mais concentrado em regiões específicas, especialmente na Europa e na Ásia, além de nos Estados Unidos, essas companhias estão se voltando para a constituição de parques produtivos próximos desses mercados. O crescimento das novas tecnologias, baseadas na conectividade da internet e na inteligência artificial, especialmente a partir do avanço da produção via internet das coisas, liberará cada vez mais essas empresas da necessidade de acessar mão de obra barata nos países mais pobres. A China, novamente, teve uma capacidade estratégica de se antecipar a este processo, construindo uma transição de um modelo de importação de matériasprimas e peças para montagem de produtos voltados à exportação rumo a um novo padrão de produção de bens sofisticados. Além disso, a China começa a priorizar seu gigantesco mercado interno de consumo. Há uma demanda interna crescente: “A maior parte dos produtos feitos na China são vendidos no mercado interno, com uma impressionante inversão da curva em dez anos: em 2007, o país exportava 55 por cento de seus bens eletrônicos produzidos e 37 por cento dos produtos têxteis. Em 2017, respectivamente, esses números mudaram para 29 e 17 por cento” (LUND, MANYIKA e SPENCE, 2019, p. 123). ${ }^{4}$

Analisando a área da ciência no país na década anterior, Pedrosa e Chaimovich (2015) mostram que, a despeito de louváveis tentativas de políticas públicas com impactos na área (o Plano Nacional de Educação 2011-2020, por exemplo) e da busca por novos modelos de governança em Ciência Tecnologia e Inovação (CT\&I) - com mudanças na legislação e a criação de organizações sociais para simplificar a gestão, por exemplo -, essas tentativas tiveram pouco efeito em reverter impasses que já duram décadas. Um desses indicadores é a produtividade do trabalho, que continua estagnada desde os anos 80 do século passado. O Brasil seguiu a lógica predominante na América Latina, onde o aumento dos gastos sociais não teve reflexo na melhoria da produtividade do trabalho - com a exceção do Chile, que a dobrou entre 1980 e 2010. Na verdade, houve retrocesso na taxa média de produtividade, conforme sustentam os autores: 'Nem o 'boom' das commodities entre 2004 e 2010 fez diferença. Parte da explicação para o baixo desempenho do Brasil, mesmo durante aquele ciclo de crescimento, reside no fato de que a maior parte do crescimento econômico

${ }^{4}$ Tradução livre do autor. 
ao longo desses anos veio da indústria de serviços; uma vez que esse setor exige menos qualificação, a produtividade média dos trabalhadores na verdade caiu" (PEDROSA e CHAIMOVICH, 2015, p. 40).

Não há consenso sobre os motivos de tal estagnação, que, na prática, condenou o Brasil à paralisia estratégica após o esgotamento do ciclo de substituição de importações. Alguma equação não foi fechada no terreno político e institucional, fazendo com que as sucessivas políticas aplicadas não alcançassem melhores resultados. Não foi por ausência de produção intelectual e da elaboração de estudos, especialmente por parte da qualificada burocracia estatal. Antes do lançamento da ENCTI, por exemplo, outro documento produzido na Secretaria de Assuntos Estratégicos da Presidência da República, sob a coordenação de Mangabeira Unger, fez um consistente diagnóstico a respeito dos dilemas do setor produtivo do país, sugerindo, também, caminhos para uma nova inserção das empresas brasileiras nas cadeias globais, por meio do que o autor vem defendendo como empreendedorismo de vanguarda. Caracterizando a situação do Brasil como de primitivismo produtivo, o texto afirma que, na média, as grandes empresas nacionais são tecnologicamente atrasadas, enquanto as pequenas são totalmente atrasadas, operando entre a informalidade e a ilegalidade. Para superar essa situação, a proposta aponta um conjunto ambicioso de modificações institucionais, com foco em políticas voltadas à geração de uma rede de empresas médias avançadas como caminho para alcançar novas vantagens comparativas na economia mundial (BRASIL, 2015).

\section{Esforços institucionais nas décadas recentes}

Nas duas primeiras décadas deste século, ocorreram inúmeras iniciativas de modificação do reordenamento no aparato legal com o objetivo de criar condições para um maior dinamismo de setor de ciência tecnologia e inovação do país. Essas iniciativas visaram especialmente a uma maior aproximação entre o setor público, a academia e o mundo privado. Ampliou-se o compartilhamento de responsabilidades entre os entes federativos a partir de mudanças legislativas tanto no âmbito federal quanto estadual. As fundações de amparo tiveram um forte protagonismo no encaminhamento dessa agenda legislativa, a partir do trabalho do Conselho Nacional das Fundações Estaduais de Amparo à Pesquisa (CONFAP). ${ }^{5}$ A mudança mais significativa foi a aprovação da Lei $\mathrm{n}^{\mathrm{o}}$ 13.243, de 11 de janeiro de 2016, que modificou significativamente a Lei de Inovação.

A Lei 13.243/2016 foi regulamentada em fevereiro de 2018, após dois anos de negociações envolvendo a comunidade científica, o setor empresarial, fundações de amparo à pesquisa e o governo, por meio do Decreto $n^{\circ} 9.283$. Essa nova regulamentação consolida e amplia o olhar para

${ }^{5}$ O CONFAP foi criado em 2006 e congrega 26 fundações de amparo à pesquisa (FAPs). Ele é o espaço institucional de articulação das FAPs, propiciando uma cooperação horizontal dentro de sistema subnacional de ciência e tecnologia. 
os sistemas regionais. O decreto estabelece: "medidas de incentivo à inovação e à pesquisa científica e tecnológica no ambiente produtivo, com vistas à capacitação tecnológica, ao alcance da autonomia tecnológica e ao desenvolvimento do sistema produtivo nacional” (BRASIL, 2018). Abriu-se, formalmente, a possibilidade de o país alterar seu padrão histórico de dissociação entre academia, centros de pesquisas e empresas. Novos instrumentos podem ser desenvolvidos na articulação de políticas de fomento, facilitando a aproximação entre pesquisa básica e pesquisa aplicada. Também as empresas, especialmente as de menor porte, podem se aproximar do universo da pesquisa, agregando valor e melhorando seus produtos e serviços.

A questão, porém, é saber se esses novos instrumentos serão realmente utilizados a contento e terão impacto positivo, alterando o padrão estagnante identificado por Pedrosa e Chaimovich, e criando uma nova lógica na área de ciência, tecnologia e inovação no país. Obviamente, não é possível responder a priori essa pergunta, mas o histórico das décadas recentes sugere imensas dificuldades que precisam ser superadas. Falta, ainda, uma estratégia consistente, a qual só tem chance de êxito se for claramente compreendida e compartilhada por um conjunto de atores institucionais, sociais e políticos relevantes. E para que isso ocorra, em algum momento será necessário romper com o caráter insular que caracteriza a ciência e a pesquisa no país, criando, na esfera pública, o reconhecimento do caráter estratégico da área.

Essa necessária estratégia, obrigatoriamente, vai retomar o debate sobre o papel do Estado e demais atores no arranjo institucional mais viável. Nesse sentido, é sempre imperativo fazer opções. A crítica de Rodrik (2011) à opção pela abertura total na lógica de uma hiperglobalização, por exemplo, parece-nos um roteiro adequado para se pensar, em tese, no que pode ser feito no Brasil nos próximos anos, vislumbrando um cenário para a Agenda 2030 em relação à área de pesquisa e inovação. Seus estudos desmontam, com evidências, alguns mitos a respeito da capacidade de o mercado encaminhar isoladamente qualquer alternativa de transição a um padrão mais elevado de desenvolvimento e inserção nas cadeias produtivas globais. Rodrik se afasta tanto dos liberais, que advogam acriticamente as vantagens da liberação total dos mercados e da desregulamentação das economias, quanto das análises que não reconhecem os ganhos de algumas regiões na globalização, nas décadas recentes, no contexto da economia capitalista. Para embasar sua análise, reconstitui os caminhos da ordem, que, por mais de três décadas, propiciou espaços de relativa autonomia aos Estados nacionais para optarem dentro de suas condições específicas para construírem - em alguns países - experiências distintas de Estados de Bem-Estar. Esse processo ocorreu, com maior intensidade, nas economias centrais do capitalismo, mas, também, em caráter mais limitado, em alguns países em desenvolvimento que experimentaram processos de crescimento e industrialização. Para fazer escolhas, enfrentando os desafios pontuados por Rodrik, o Brasil precisa antes escapar de um 
dilema de maior impacto, conforme descreve Arbix (2009; 2017), isto é, precisa adquirir capacidade de entrar no jogo antes que as janelas de oportunidades para os países em desenvolvimento se fechem de vez. Arbix mostra como esse processo está se acelerando com transformações do universo produtivo. São claros os impactos negativos no mercado de trabalho e o aumento da concorrência entre os trabalhadores, ampliando a desigualdade entre os mais e menos qualificados. São ameaças que poderão ser amplificadas, nos próximos anos, caso nossa economia não responda em seu conjunto - ou, ao menos, na maioria de seus setores -, aos desafios impostos pelo ritmo da revolução produtiva.

O país vivencia um longo período de desindustrialização e estagnação, embora tenha experimentado políticas importantes de proteção social, nas duas décadas recentes. Mas precisa encontrar um caminho para se reindustrializar em novas bases competitivas tanto para suas empresas nacionais quanto para as multinacionais aqui instaladas, que também contam com plantas industriais obsoletas (BRESSER-PEREIRA, 2018). Caso contrário, sua competitividade ficará restrita ao segmento de commodities. Nesse sentido, o papel estratégico aqui pensado para as FAPs pressupõe um cenário de reversão dessa tendência de ameaça presente na análise conjuntural de curto e médio prazos. Tomando como exemplo alguns cenários de prospecção em estudo do Ipea/Assecor (2017), essa agenda só poderá ser viabilizada a partir de uma variável democrática de conciliação entre políticas econômicas e sociais, articuladas com uma estratégia de crescimento sustentável. Essa combinação positiva dependeria de uma coordenação longa e exitosa entre investimentos públicos e privados, capazes de construir suporte para uma sociedade inovadora e dinâmica, compromissada com o desenvolvimento em sentido amplo.

$\mathrm{Na}$ hipótese de encaminhamento de decisões estratégicas que favoreçam tal cenário, as fundações de amparo à pesquisa podem desenvolver múltiplas ações capazes de contribuir com objetivos mais audaciosos na área de pesquisa e inovação. Entre outras atividades estratégicas, elas podem ampliar a atuação das agências federais em temas como difusão científica, apoio a programas de pós-graduação, mestrados profissionais, iniciação científica, mobilidade acadêmica, na linha de internacionalização das universidades, capacitação, pesquisa e inovação em ambientes produtivos. Construir infraestruturas resilientes, promover uma industrialização inclusiva e fomentar a inovação não são tarefas triviais. São tarefas que demandarão esforços institucionais e políticos gigantescos.

\section{Percepções de atores-chave}

As percepções do que estamos qualificando como atores-chave do sistema subnacional brasileiro de ciência, tecnologia e inovação foram captadas em três etapas. Na primeira etapa, foram 
realizadas três entrevistas em profundidade, respectivamente, com o diretor responsável pela cooperação com as fundações no Conselho Nacional de Desenvolvimento Científico e Tecnológico CNPq (SANTANA, 2018), com o representante da maior fundação estadual de amparo à pesquisa (PACHECO, 2018) e com a presidente do Conselho Nacional das Fundações Estaduais de Amparo à Pesquisa - CONFAP (TURCHI, 2018). Em seguida, uma pesquisa qualitativa foi aplicada a todas as fundações estaduais. E na terceira etapa, foram feitas duas novas entrevistas em profundidade para discutir os resultados das etapas anteriores. Esse diálogo teve como objetivo explorar possíveis caminhos para fortalecer o papel das fundações estaduais de amparo na consolidação de sistemas de apoio à pesquisa e à inovação, explorando os temas da Agenda 2030 das Nações Unidas. Procuramos identificar e descrever suas especificidades, buscando uma avaliação comparada em duas dimensões. A primeira, por meio de uma análise sequencial (MAHONEY et al., 2003) que considerou os desdobramentos dos processos de afirmação das FAPs, no início da expansão do sistema, logo após a promulgação da Constituição de 1988, e até as ações institucionais mais recentes de reorganização do marco legal em que elas operam. A segunda, voltada à identificação de processos específicos que se mostraram relevantes para uma comparação direta individualizadora (TILLY, 1984) - por exemplo, a existência ou não de densidade acadêmica e de pesquisa no território em que atuam, e a comparação com arranjos institucionais de outros países.

Apoiada também pela literatura e por dados secundários, essa metodologia orientou as três entrevistas preliminares, as quais abordaram temas como financiamento, integração universidadeempresas, tecnologia social, institucionalização e cooperação internacional, e tiveram como objetivo a própria orientação da pesquisa com base nos primeiros sinais do levantamento empírico, conforme sugere Layder (1993). A partir dessas entrevistas, foi desenvolvido um instrumento de pesquisa por meio de questionário, que foi aplicado aos novos dirigentes das FAPs durante o ano de 2019. As respostas recebidas levantaram novos e importantes temas. No entanto, o baixo número de respondentes não permitiu generalizar percepções capazes de representar o universo do sistema subnacional. Dessa forma, optou-se pela realização de novas entrevistas em profundidade com outros atores ocupantes de posições estratégicas dentro do sistema - Gargioni (2019); Vilela (2019) -, além da ampliação da análise da literatura e do contexto. Há uma clara dificuldade de levantamento de dados e sistematização da experiência das fundações estaduais. O próprio CONFAP não conseguiu ainda sistematizar informações agregadas mais recentes sobre os recursos executados por todas as FAPs. Os dados mais atuais disponíveis retratam a situação de uma década atrás (CONFAP, 2009). Em 2018 foi iniciado um promissor projeto de portal integrado com os dados da área de ciência, tecnologia e inovação do país, envolvendo as agências federais e as FAPs. Sua viabilização cumpriria um papel importante para a ciência no país. 
O instrumento utilizado para captar as percepções estratégicas dos dirigentes máximos que estão ou estiveram à frente dessas instituições nos últimos quatro anos foi um questionário semiestruturado, com escala de concordância ${ }^{6}$ a partir de afirmações genéricas amarradas a temas centrais, além de um espaço optativo para comentários. O primeiro tema abordou a trajetória das fundações estaduais após o processo constituinte de 1988. O segundo bloco apresentou perguntas testando o nível de compreensão e concordância com as linhas gerais da Estratégia Nacional de Ciência e Tecnologia, lançada em 2016 pelo governo federal. O terceiro explorou temas da Agenda 2030 das Nações Unidas, na área de ciência, tecnologia e inovação. E o quarto e último bloco tratou das questões institucionais específicas de cada fundação. A impossibilidade de apontar tendências mais fortes com esse questionário foi parcialmente suprida por outra pesquisa simultânea com temas conexos, desenvolvida pelo autor para o Centro de Gestão e Estudos Estratégicos (CGEE) em 2019, que abordou o financiamento das FAPs nas áreas de humanidades. Os dados dessa pesquisa permitem-nos sistematizar algumas percepções importantes para esta discussão, pois foram gerados a partir da resposta de dez fundações estaduais, incluindo as duas maiores em termos de recursos e projetos: a Fundação de Amparo à Pesquisa do Estado de São Paulo (FAPESP) e a Fundação de Amparo à Pesquisa do Estado de Minas Gerais (FAPEMIG).

Um tema relevante e conexo das duas pesquisas pode ser localizado nas prioridades de financiamento por parte das fundações. Nesse caso, inovação e qualificação profissional aparecem com grande destaque, conforme se vê na Tabela 1 abaixo. A inovação é um tema de grande amplitude, pois inclui dimensões variadas em relação a produtos, processo e governança, tanto na área pública quanto privada. No conceito schumpeteriano, seu locus é a empresa, ao passo que no sistema de CT\&I, ele é mais difuso (com papel proeminente para a produção de conhecimento) e a inovação, propriamente dita, é condicionada pelo resultado econômico. Nesse caso são incluídos, também, os procedimentos e a introdução de novas ferramentas na gestão pública, alargando-se o sistema para além da delimitação schumpeteriana. Nessa pesquisa, trata-se de uma ressalva importante para se compreender o alto percentual alcançado nas respostas (CGEE, 2019).

Tabela 1 - Temas relevantes para financiamento (respostas múltiplas)

\begin{tabular}{|c|c|}
\hline Tema & $\%$ de respostas \\
\hline Inovação & 31 \\
\hline Outros & 24,1 \\
\hline Investimento em qualificac̃o profissional & 13,8 \\
\hline Políticas sociais & 10,3 \\
\hline Meio ambiente e mudança climática & 10,3 \\
\hline Aumento da produtividade & 6,9 \\
\hline Qualidade das instituições públicas & 3,6 \\
\hline Total & $\mathbf{1 0 0}$ \\
\hline
\end{tabular}

Fonte: CGEE, 2019; Survey com as fundações estaduais.

\footnotetext{
${ }^{6}$ Uso da Escala Likert para buscar capturar e matizar a intensidade das opiniões dos entrevistados.
} 
Uma questão central que se coloca cada vez mais para as FAPs, na medida em que o sistema subnacional ampliou, nos anos recentes, a sua participação no financiamento de pesquisa e inovação no país, diz respeito às críticas quanto aos resultados modestos das inúmeras políticas de inovação adotadas nas duas décadas anteriores, as quais não foram capazes de propiciar resultados mais satisfatórios, rompendo com o cenário de estagnação em diversos indicadores. Negri (2017) sustenta que esses resultados modestos se devem, principalmente, a dois fatores: um ambiente institucional rígido e burocrático, associado a uma economia fechada e pouco competitiva. O segundo fator retrataria as deficiências das políticas de inovação, pois, a despeito da utilização dos instrumentos amplamente testados em outros países - como crédito subsidiado, incentivos fiscais e subvenções -, os resultados indicariam uma ausência de orientação estratégica.

Conforme mencionado acima, uma tentativa de desenho de estratégia - pelo menos em relação aos temas - foi a Estratégia Nacional de Ciência, Tecnologia e Inovação (ENCTI), lançada em 2016. A Tabela 2 mostra os temas priorizados pelas FAPs. Os dois primeiros apontados são saúde e alimentos, com 25\% e 17,5\%, respectivamente. Em terceiro e quarto lugar, aparecem água e biomas e bioeconomia. Observa-se que são temas relevantes para o bem-estar social, como saúde e alimentos, e para o meio ambiente. $\mathrm{O}$ tema das ciências e tecnologias sociais possui um percentual mais alto de respostas $(7,5)$ do que o tema da economia e sociedade digital (5). São temas mais relacionados à pesquisa pública para aplicação em soluções coletivas do que temas mais relacionados à inovação.

Tabela 2 - Temas ENCTI (respostas múltiplas)

\begin{tabular}{|l|l|}
\hline \multicolumn{1}{|c|}{ Tema ENCTI } & \multicolumn{1}{c|}{$\%$ de respostas } \\
\hline Saúde & 25 \\
\hline Alimentos & 17,5 \\
\hline Água & 15 \\
\hline Biomas e bioeconomia & 12,5 \\
\hline Ciências e tecnologias sociais & 7,5 \\
\hline Aeroespacial e defesa & 5 \\
\hline Economia e sociedade digital & 5 \\
\hline Energia & 5 \\
\hline Clima & 2,5 \\
\hline Minerais estratégicos Total & 2,5 \\
\hline Tecnologias convergentes e habilitadoras & 2,5 \\
\hline \multicolumn{2}{|c|}{100} \\
\hline
\end{tabular}

Fonte: CGEE, 2019.

Ainda em relação ao financiamento, outras duas questões aparecem nas entrevistas com atores do sistema subnacional, bem como na literatura nacional recente, que analisa os impactos das políticas adotadas nos anos recentes. Trata-se da necessidade de novas políticas com recursos em volumes relevantes e focadas em projetos com capacidade para resolver problemas centrais da sociedade em geral, bem como dilemas específicos de políticas públicas das regiões. Havendo esses 
recursos (hoje não disponíveis a contento), coloca-se uma questão importante no terreno da coordenação. Confrontadas com esses temas, as FAPs ofereceram respostas a esses itens na Tabela 3, a qual revela uma medida de inconsistência nas respostas em relação à complementaridade ou sobreposição do financiamento. A mediana '2' para o item sobre identificação de demandas não atendidas indica maior discordância do que concordância. No entanto, a mediana '4' (próxima de concordo totalmente) corresponde aos itens relacionados com a complementaridade entre agências nacionais e fundações estaduais no financiamento à pesquisa e à priorização do financiamento aos temas e problemas do estado ou região.

Tabela 3 - Percepção sobre financiamento

\begin{tabular}{|l|l|}
\hline \multicolumn{1}{|c|}{ Item } & \multicolumn{1}{|c|}{$\begin{array}{c}\text { Mediana* } \\
\text { (entre 1 e 5) }\end{array}$} \\
\hline $\begin{array}{l}\text { Existe uma sobreposição de temas e áreas de conhecimento nos editais de } \\
\text { financiamento à pesquisa pelas fundações de amparo à pesquisa e pelas } \\
\text { agências de fomento em nível nacional. }\end{array}$ & 3,5 \\
\hline $\begin{array}{l}\text { O financiamento da fundação de apoio do meu estado procura identificar } \\
\text { as demandas não atendidas pelos editais das agências nacionais de fomento. }\end{array}$ & 2 \\
\hline $\begin{array}{l}\text { Existe uma complementaridade entre a fundação de apoio no meu estado e } \\
\text { as agências nacionais de fomento no financiamento à pesquisa. }\end{array}$ & 4 \\
\hline $\begin{array}{l}\text { O financiamento da fundação de apoio do meu estado prioriza o financia- } \\
\text { mento à pesquisa relacionada com temas e problemas da região. }\end{array}$ & 4 \\
\hline
\end{tabular}

Fonte: CGEE, 2019.

*Escala do tipo Likert em que '1' é discordo totalmente e '5' é concordo totalmente.

Pesquisas com foco na solução de problemas (mission-oriented research) exigem uma coordenação para além de recursos e definição de prioridades. Passam, também, por uma compreensão mais ampla da interdisciplinaridade, implicando mudanças mais profundas na criação de novas tecnologias e a ampliação da capacidade de coordenação entre diferentes atores (MAZZUCATO; PENNA, 2015). A Tabela 4 evidencia uma alta concordância com esses propósitos por uma mediana '2' (próximo de discordância total) em relação à diminuição do papel das ciências humanas, e uma mediana '5' (alta concordância) em relação à abordagem interdisciplinar. Por outro lado, mostra a mediana ' 3 ' para a pesquisa orientada à solução de problemas (não concorda nem discorda) o que pode significar uma posição de indiferença. 
Tabela 4 - Percepção sobre relação entre pesquisa e políticas públicas

\begin{tabular}{|l|l|}
\hline \multicolumn{1}{|c|}{ Item } & $\begin{array}{c}\text { Mediana* } \\
\text { (entre 1 e 5) }\end{array}$ \\
\hline O comportamento social é fundamental para o sucesso das políticas públicas. & 5 \\
\hline $\begin{array}{l}\text { As dificuldades de mobilidade urbana comprometem a inserção laboral e edu- } \\
\text { cacional dos jovens. }\end{array}$ & 5 \\
\hline $\begin{array}{l}\text { Os programas de apoio ao emprego de jovens em seu estado contribuem para } \\
\text { o aperfeiçoamento profissional e a mobilidade social da juventude. }\end{array}$ & 5 \\
\hline $\begin{array}{l}\text { A sociedade brasileira não valoriza o desenvolvimento tecnológico e a inova- } \\
\text { ção porque não percebe o papel da inovação e da tecnologia em suas vidas. }\end{array}$ & 4 \\
\hline $\begin{array}{l}\text { As humanidades possuem enorme dificuldade em gerar respostas para pro- } \\
\text { blemas práticos da sociedade. }\end{array}$ & 2 \\
\hline $\begin{array}{l}\text { A perda da formação cultural e linguística na sociedade diminui nossa inteli- } \\
\text { gência coletiva. }\end{array}$ & 5 \\
\hline $\begin{array}{l}\text { O fomento das FAPs deveria ser, preferencialmente, orientado à solução de } \\
\text { problemas. }\end{array}$ & 3 \\
\hline $\begin{array}{l}\text { O fomento das FAPs deveria incentivar a integração de conhecimentos das } \\
\text { diferentes áreas, tendo em vista que os problemas quase sempre exigem uma } \\
\text { abordagem interdisciplinar. }\end{array}$ & 5 \\
\hline
\end{tabular}

Fonte: CGEE, 2019.

*Escala do tipo Likert em que ' 1 ' é discordo totalmente e '5' é concordo totalmente.

Por fim, outra questão testada nesta pesquisa foi a cooperação entre universidades a partir da Lei de Inovação. Esse é um enorme desafio para que a pesquisa da inovação avance no Brasil. Ao contrário de outros países, não contamos ainda com um sistema diversificado em relação às instalações de pesquisa, envolvendo instituições públicas, privadas e modelos mistos. Embora desejável, esse tipo de arranjo não será ofertado sem um acordo cooperativo. Há uma altíssima concentração dessas instalações nas instituições públicas - em especial, nas universidades públicas. Portanto, é relevante e imperativo ampliar essa cooperação, começando com a própria compreensão de seus problemas. Nesse sentido, chama a atenção na Tabela 5 a mediana "3" (tendência à indiferença) no que diz respeito ao comprometimento da autonomia na pesquisa e à dificuldade de definição dos direitos de propriedade intelectual. No caso brasileiro, essa área não está pacificada e é certamente um problema relevante na cooperação entre universidades e empresas. Assim, a mediana ' 3 ' parece sugerir pouca visibilidade aos problemas de linguagem e da própria cooperação. 
Tabela 5 - Percepção sobre cooperação entre universidade e empresa, a partir da Lei da Inovação

\begin{tabular}{|l|l|}
\hline \multicolumn{1}{|c|}{ Item } & \multicolumn{1}{|c|}{$\begin{array}{c}\text { Mediana* } \\
\text { (entre 1 e 5) }\end{array}$} \\
\hline $\begin{array}{l}\text { Muitos pesquisadores das universidades consideram que a cooperação } \\
\text { com outras organizações pode comprometer a sua autonomia na pesquisa. }\end{array}$ & 3 \\
\hline $\begin{array}{l}\text { Existe dificuldade de definir a quem pertence o direito sobre a patente re- } \\
\text { sultante do conhecimento científico desenvolvido. }\end{array}$ & 3 \\
\hline $\begin{array}{l}\text { O tempo de atendimento das demandas das empresas e o tempo necessá- } \\
\text { rio para a realização de pesquisas por parte da universidade são muito di- } \\
\text { ferentes. }\end{array}$ & 5 \\
\hline $\begin{array}{l}\text { A pesquisa em cooperação com a empresa produz poucos resultados para } \\
\text { a elaboração de publicações científicas em periódicos qualificados, em es- } \\
\text { tratos superiores. }\end{array}$ & 1 \\
\hline $\begin{array}{l}\text { Há a necessidade de maior conhecimento dos pesquisadores em como } \\
\text { proceder à gestão de pesquisas aplicadas, especialmente no caso das ciên- } \\
\text { cias humanas. }\end{array}$ & 5 \\
\hline
\end{tabular}

Fonte: CGEE,2019. Survey com as fundações estaduais.

*Escala do tipo Likert em que '1' é discordo totalmente e ‘5' é concordo totalmente.

Nas entrevistas em profundidade, as percepções dos atores consultados convergem quanto aos problemas centrais da área; em especial, em relação a seu caráter insular, que revela pouco conhecimento da sociedade sobre o seu potencial e caráter estratégico para o desenvolvimento do país. Essa é uma preocupação cada vez maior nas FAPs, e muitas delas já contam com estratégias de popularização da ciência como um caminho para se aproximarem da sociedade. A Fundação de Amparo à Pesquisa do Estado de Minas Gerais (FAPEMIG), por exemplo, tem ampliado suas iniciativas de diálogo público sobre o trabalho dos pesquisadores. Os depoimentos destacam a importância dessa aproximação com a sociedade para mostrar os avanços institucionais e as iniciativas inovadoras realizadas em contextos locais e regionais extremamente diferenciados. E algumas experiências exitosas, que contrastam com indicadores gerais de estagnação do país, mostram que isso é possível. Santa Catarina é uma dessas experiências reconhecidas, em função da consolidação de um ecossistema de inovação que foi capaz de alterar o perfil da economia da capital do estado, Florianópolis, a partir da criação de empresas de base tecnológica. Um trabalho de forte parceria entre universidade, setor privado e órgãos de fomento, incluindo a FAP estadual.

As FAPs são hoje parte indissociável do sistema nacional de ciência e tecnologia. As assimetrias, obviamente, são enormes tanto em relação às agências nacionais (com exceção da FAPESP) quanto entre as próprias fundações. As agências nacionais contam com esses entes subnacionais para implementarem suas políticas e projetos. Com diferenças de escala, praticamente todas 
as FAPs atuam na formação de recursos humanos de alta capacidade para a pesquisa, especialmente por meio de bolsas em projetos que ajudam a fixar doutores nas distintas regiões. Esse olhar para as regiões, a partir de temas estratégicos, é chave para a formação e ampliação de redes de pesquisa em um país com a diversidade e a dimensão do Brasil. Observa-se, nos últimos anos, o aumento das iniciativas de projetos de pesquisas em parceria entre as FAPs, incluindo editais em conjunto com organismos de cooperação internacional. A institucionalização das FAPs, contudo, ainda é baixa. O espaço propiciado pelo CONFAP, na década recente, contribuiu para o estabelecimento de um diálogo permanente das FAPs com as agências federais. Isso está bem assentado. Observase, também, nos últimos anos, um esforço no interior do CONFAP em prol da intensificação do diálogo horizontal entre as FAPs. Esse processo é decisivo para o estímulo à criação e à implementação de programas regionais de ciência, tecnologia e inovação.

\section{Considerações finais}

Este artigo procurou apresentar um mapa mínimo sobre as principais tendências na definição de políticas no âmbito das Fundações Estaduais de Amparo à Pesquisa (FAPs). O seu recorte teve como parâmetro as questões descritas no objetivo 9 da Agenda 2030 das Nações Unidas, adotada pelo Brasil, que trata da necessidade de construir infraestruturas resilientes, buscando promover a industrialização inclusiva e sustentável, além de fomentar a inovação. O tema foi pensado teoricamente a partir de uma revisão parcial da literatura que discute as mudanças e os riscos embutidos no processo de estruturação da sociedade do conhecimento, ou sociedade em rede, conforme argumenta Castells. Esse paradigma orientou o olhar sobre as tentativas de adequação do nosso sistema de ciência, tecnologia e inovação após a Constituição de 1988. Orientou, também, as entrevistas qualitativas realizadas com os gestores do sistema subnacional (FAPs), foco da pesquisa. O balanço é positivo pois são evidentes os sinais de esforços no plano federal, incluindo o Legislativo. E esforços ainda maiores podem ser identificados no trabalho desenvolvido em diversos estados. O Brasil buscou estruturar um sistema subnacional de apoio à pesquisa, ciência, tecnologia e inovação nas três décadas recentes. O modelo seguido se baseou no estado mais rico e industrializado da Federação, São Paulo, que conta com uma forte e vitoriosa experiência há mais de 50 anos, por meio da FAPESP. Um primeiro olhar para a trajetória das fundações estaduais estruturadas a partir da Constituição de 1998 - que necessita de novas e aprofundadas pesquisas quantitativas e qualitativas - evidencia hoje muitas carências e, ao mesmo tempo, experiências exitosas.

São perceptíveis as dificuldades da maioria das fundações para operarem com maior desenvoltura na análise e gestão de projetos de financiamento. Falta, ainda, uma maior autonomia e uma 
burocracia profissional com capacidade de gestão. O que mostram as experiências da FAPESP e de outras fundações que avançaram mais em sua estruturação é que isso só pode ocorrer a partir da construção de soluções, por meio de pesquisa, para os problemas e potencialidades reais de cada local ou região. Somente isso poderá gerar densidade, retroalimentando todo o ambiente institucional. A despeito dessas dificuldades, a experiência mostra, também, uma rica trajetória que, em si, já se constitui como um capital institucional a ser explorado. As fundações desenvolveram múltiplas ações nos anos recentes em temas como difusão científica, apoio a programas de pós-graduação, iniciação científica, mobilidade acadêmica na linha de internacionalização das universidades, capacitação, pesquisa em políticas públicas e inovação em ambientes produtivos. Trata-se de um modelo a ser reforçado, de maneira estratégica, caso o país consiga resolver seu dilema maior na geração de novas políticas no setor, capazes de romper com a estagnação diagnosticada - políticas que, como sugere Negri (2017), entre outras tarefas, consigam mobilizar recursos relevantes, facilitem o desenvolvimento de novas instituições e a geração de infraestrutura de ponta e aberta ao uso colaborativo, e concentrem o foco na solução de problemas e em temas prioritários.

\section{Referências}

ARBIX, Glauco. Dilemas da inovação no Brasil. In: TURCHI, Lenita M.; MORAES, José Mauro de (Org.). Políticas de apoio à inovação tecnológica no Brasil: avanços recentes, limitações e propostas de ações. Brasília: Ipea, 2017, p. 47-80.

ARBIX, G. et al (Org.). Estratégias de inovação em sete países: EUA, Canadá, Irlanda, França, Reino Unido, Finlândia e Japão. Brasília: ABDI, 2009.

BAUMAN, Zygmunt. Modernidade líquida. Rio de Janeiro: Zahar, 2001.

BRASIL. Presidência da República. Produtivismo includente: empreendedorismo vanguardista. Brasília: Secretaria de Assuntos Estratégicos, Subsecretaria de Ações Estratégicas, 2015.

BRASIL. Ministério das Relações Exteriores. Transformando nosso mundo: a Agenda 2030 para o Desenvolvimento Sustentável. Brasília: MRE, 2016. Disponível em: http://www.itamaraty.gov.br /images/ed_desenvsust/Agenda2030completoportugus12fev2016.pdf.

BRASIL. Ministério da Ciência e Tecnologia. Tecnologia, inovação e comunicações. Estratégia Nacional de Ciência Tecnologia e Inovação 2016-2022. Brasilia: MCT, 2016a.

BRASIL. Presidência da República. Decreto n. 9.283, de 07 de fevereiro de 2018. Disponível em: http://www.planalto.gov.br/ccivil_03/_Ato2015-2018/2018/Decreto/D9283.htm?

BRESSER-PEREIRA, Luiz Carlos. Em busca do desenvolvimento perdido: um projeto novodesenvolvimentista para o Brasil. Rio de Janeiro: FGV, 2018. 
CASTELLS, Manuel. A era da informação: economia, sociedade e cultura. Volume I (A sociedade em rede); Volume II (O poder da identidade); Vol. III (O fim do milênio). Lisboa: Fundação Calouste Gulbenkian, 2011.

CGEE. Financiamento estadual à pesquisa acadêmica nas áreas de Ciências Humanas; Sociais Aplicadas; Linguística; Letras e Artes. Relatório de Pesquisa. Brasília: Centro de Gestão e Estudos Estratégicos, 2019.

CONFAP. Fundações Estaduais de Amparo à Pesquisa: orçamento executado 2007-2009. Brasília: Conselho Nacional das Fundações Estaduais de Amparo à Pesquisa, 2009 (pdf).

NEGRI, Fernanda de. Por uma nova geração de políticas de inovação no Brasil. In: TURCHI, Lenita M.; MORAES, José Mauro de (Org). Políticas de apoio à inovação tecnológica no Brasil: avanços recentes, limitações e propostas de ações. Brasília: Ipea, 2017, p. 25-46.

EUROPEAN COMMISSION. Open innovation, open Science, open to the world: a vision for Europe. Brussels: European Commission, Directorate-General for Research and Innovation, 2016.

GAETANI, Francisco; ALMEIDA, Virgílio. O avanço digital e a natureza do trabalho em mutação. Valor Econômico, 7 dez. 2019. Disponível em: http://www.valor.com.br.

GARGIONI, Sergio Luiz (Ex-presidente da Fundação de Amparo à Pesquisa e Inovação de Santa Catarina - FAPESC - e ex-presidente do Conselho Nacional das Fundações Estaduais de Amparo à Pesquisa - CONFAP). Entrevista cedida em 15 jul. 2019.

GIANNOTTI, José A.; MOUTINHO, Luiz Damon S. Os limites da política: uma divergência. São Paulo: Companhia das Letras, 2017.

IPEA e ASSECOR. Brasil 2035: cenários para o desenvolvimento. Brasília: Instituto de Pesquisa Econômica Aplicada / Associação Nacional dos Servidores da Carreira de Planejamento e Orçamento, 2017.

LAYDER, Derek. New strategies in social research: an introduction and guide. Cambridge: Polity Press, 1993.

PEDROSA, Renato Hyuda de Luna; CHAIMOVICH, Hernan. Relatório Brasil. In: Relatório de ciência da Unesco. Rumo a 2030. Visão geral e cenário brasileiro. Brasília: Unesco, 2015.

LUND, Susan; MANYIKA, James; SPENCE, Michael. The Global Economy's Next Winners. Foreign Affairs, July-August/2019, p. 121-130.

MAHONEY, James et al. Comparative historical analysis in the social sciences. New York: Cambridge University Press, 2003.

MAZZUCATO, Mariana; PENNA, Caetano (eds.). Mission-oriented finance for innovation. New ideas for investment-led growth. London: Rowman \& Littlefield International, 2015.

PACHECO, Carlos Américo (Diretor-presidente da Fundação de Amparo à Pesquisa do Estado de São Paulo - FAPESP). Entrevista cedida em 13 dez. 2018. 
RODRIK, Dani. The globalization paradox: why global markets, states, and democracy can't coexist. Oxford: Oxford University Press, 2011.

RODRIK, Dani. Economics rules: the rights and wrongs of the dismal science. New York: W.W Norton \&, Company,2015.

RODRIK, Dani. Só inovação não basta. Valor Econômico, 10 jun. 2016, p. A15.

SAAD FILHO, Alfredo; MORAIS, Lecio. Brasil: neoliberalismo versus democracia. São Paulo: Boitempo, 2018.

SANTANA, Jose Ricardo de (Diretor de Cooperação Institucional do Conselho Nacional de Desenvolvimento Científico e Tecnológico - CNPq). Entrevista cedida em 16 nov. 2018.

TILLY, C. Big structures, large processes, huge comparisons. New York: Russel Sage, 1984.

TURCHI, Maria Zaira (Presidente da Fundação de Amparo à Pesquisa do Estado de Goiás - FAPEG - e do Conselho Nacional das Fundações Estaduais de Amparo à Pesquisa - CONFAP). Entrevista cedida em 20 dez. 2018.

VILELA, Evaldo Ferreira (Presidente da Fundação de Amparo à Pesquisa do Estado de Minas Gerais - FAPEMIG - do CONFAP). Entrevista cedida em 17 jul. 2019. 